\title{
Divorce, Remarriage and Welfare: A General Equilibrium Approach
}

\author{
Pierre-Andre Chiappori* and Yoram Weiss $^{\dagger}$
}

December 2005

\begin{abstract}
Modern marriage markets display increasing turnover, with less marriage but more divorce and remarriage. As a consequence, a large number of children live in single parent and step parent households. We summarize here a general equilibrium approach that allows welfare evaluations. In the absence of children, we show that higher aggregate divorce may raise welfare, because it facilitates remarriage. Even children may be better off at high divorce-remarriage environment, because of stronger incentives for fathers to transfer money to the custodial mothers.
\end{abstract}

Columbia University, pc2167@columbia.edu

Tel Aviv University, weiss@post.tau.ac.il 


\section{Introduction}

The last century has been characterized by changes in family structure, including a reduction in marriage and fertility and increased marital turnover. Divorce has been rising throughout the century and more men and women are now divorced and unmarried. However, the higher divorce rate is associated with an increase in remarriage rates. Both remarriage and divorce rates are substantially higher among recent cohorts and most divorcees remarry, suggesting that, despite the large turnover, marriage is still the "natural" state. One consequence of higher turnover is the large number of children who live in single parent and step parent households. There is substantial evidence that children of divorced parents do not

perform as well as comparable children in intact families. However, the impact of the aggregate divorce rate on transfers and the welfare of children is more difficult to assess. In this paper, we propose a theoretical framework for such an analysis.

The main ingredients of our approach can be summarized as follows. The gains from marriage include a systematic element and a random element which is realized after some time elapses. The systematic element in our model is the economic gain from sharing consumption by married partners and the gains from having children. The random element is the emotional feelings that the partners 
have about each other. Marriage is an "experience good" and couples with a low realized quality of match may wish to break their marriage and seek a better match. However, the ability to find a better match depends on the choice of others to break their marriage; moreover, the gains from remarriage will depend on the commitments that potential mates have made to their ex-spouses. This interdependence generates two basic externalities; a meeting externality, associated with the positive impact of divorce on the remarriage prospects of others, and a contract externality, reflecting the negative impact of commitments to the present spouse on the welfare of prospective matches.

Children are a collective good for their natural parents and both care about their welfare. This remains true whether the parents are married or separated. However, separation may entail an inefficient level of expenditures on children for several reasons. If the custodial parent remains single, not only does she lose the gains from joint consumption, but she may also determine child expenditures without regard to the interest of the ex-spouse. If she remarries, the presence of a new spouse who cares less about step children reduces the incentives to spend on children from previous marriages. Finally, parents that live apart from their children can contribute less time and goods to their children and may derive less satisfaction from them. These problems are amplified if the partners differ in 
income and cannot share custody to overcome the indivisibility of children. The custodial parent is usually the mother who has some comparative advantage in caring for children but has lower income. The father has often limited access to the children and lower incentive to provide for them. The outcome is that the level of child expenditures following separation is generally below the level that would be attained in an intact family, reducing the welfare of the children and possibly of their parents.

To mitigate these problems, the partners have an incentive to sign binding contracts that will determine some transfers between the spouses. The purpose of the transfers is to induce an efficient level of child expenditures following divorce. We focus here on contingent contracts, in which the father commits to pay the mother some payment if and only if she remains single. Such a commitment has two effects. First, and quite obviously, it may induce higher expenditures on the children if the mother remains single, provided that the income elasticity of child expenditures is positive. Secondly, it increases the mother's bargaining power if she remarries, which again entails higher child expenditures in this case. We show, in particular, that the incentive for such commitments is stronger when the prospects of remarriage are higher, because then the father is less likely to pay but more likely to benefit from his commitment. In addition, the incentive 
of each father to make such commitment depends on the commitments made by other fathers to their ex-wives, because such commitments also influence the bargaining outcome upon remarriage. We provide a general equilibrium framework that accounts for the feedbacks from aggregate divorce and remarriage to the individual decisions to marry, divorce and commit on transfers.

We shall discuss separately the cases with and without children. The presentation that follows draws heavily on our previous work Chiappori and Weiss (2003, 2005) and the interested reader should refer to these papers for further motivation and relevant references.

\section{Marriage and divorce without children}

\subsection{Assumptions}

\subsubsection{Incomes and preferences}

We consider homogenous population, where all individuals have the same income, $y$, and the same preferences. Utility is linear in the single consumption good, and monetary and non monetary considerations are additive. The consumption good is publicly consumed within the household; therefore, the per period utility of each married person is 


$$
u=2 y+\theta
$$

where $\theta$ represents the quality of the match. In contrast, the utility of an unmarried person is

$$
u=y \text {. }
$$

The quality of match, $\theta$, is an independent draw from a given symmetric distribution $F(\theta)$ with zero mean. By assumption, the two partners of a given marriage have the same evaluation of the match quality and successive draws of $\theta$ by a given agent in different marriages are independent. In particular, a previous divorce conveys no signal about the 'quality' of a potential spouse.

\subsubsection{Timing}

Individuals live two periods and marriage is defined as a commitment that must last for at least one period, without "search on the job". At the beginning of period 1, each single person meets another single from the population of the opposite sex of the same age and the matched partners decide whether to form a marriage union. At the end of period 1, the quality of match is revealed. Based on the information on the quality of match, agents decide at the beginning of the second 
period whether to remain married or to divorce their current partner. If the marriage dissolves, the partners immediately enter the marriage market to seek a new mate. A partner that finds no single mate of the opposite sex remains single for the rest of his $\backslash$ her life. If a meeting does occur, each party decides whether to remarry or remain single in the second period. At that time, the marital status of their ex-spouses is not yet known.

\subsubsection{Matching}

There are equal numbers of males and females in each cohort. In the first period, every agent, when matched with a single agent of the opposite sex, chooses to marry. ${ }^{1}$ Following divorce, each partner can only remarry another divorcee from the same cohort. However, the search process involves frictions. Remarriage is neither immediate nor certain: after a divorce, agents may fail to meet an eligible new mate and remain single. If a meeting occurs the partners will remarry, again because the systematic gain from marriage is positive and $E(\theta)=0$.

A key ingredient of the model is that the probability of remarriage rises with the average divorce rate in the population: remarriage is easier, the larger the number of singles around. There are several reasons why such increasing returns

\footnotetext{
${ }^{1}$ The monetary gain from marriage is positive; so is the expectation of the non monetary gain, because of the option value of divorcing if the realized quality of the match is low.
} 
should be present in our context. One is that although the two sexes meet in a variety of occasions (work, sport, social life, etc.) many of these meetings are "wasted", in the sense that one of the individuals is already attached and not willing to divorce. Obviously, 'non-wasted' meeting are more frequent when the proportion of divorcees in the population is larger. Another reason is that the establishment of more focused channels, where singles meet only singles, is costly and they will be created only if the "size of the market" is large enough. Thirdly, as noted by Mortensen (1988), the search intensity of the unattached decrease with the proportion of attached people in the population. The reason for that is that attached individuals are less likely to respond to an offer, which lowers the return for search.

We thus assume that the probability of finding an eligible new mate, denoted by $m$, is an increasing function of the divorce rate in the population, denoted by $d:$

$$
m=\phi(d), \text { with } \phi^{\prime}>0 .
$$

We may refer to the function $\phi(d)$ as the matching function. Because couples that meet always remarry, the remarriage probability is

$$
p=m=\phi(d) .
$$




\subsection{Divorce and remarriage}

The expected gains from remarriage, conditioned on meeting, is the added income that the new spouse bring into marriage, $y$. The expected utility of a single person in the second period, evaluated at separation is, therefore,

$$
y+p y \text {. }
$$

Divorce occurs if

$$
2 y+\theta<y+p y
$$

We denote the critical value of $\theta$ such that lower values of $\theta$ trigger divorce by $\theta^{*}(p)$. That is,

$$
\theta^{*}(p)=-y(1-p)
$$

Only negative realizations $\theta$ trigger divorce because the systematic gains from marriage are positive. The trigger function $\theta^{*}(p)$ rises in $p$, because the gains from divorce are higher if the prospects of finding a new mate rise. 


\subsubsection{Equilibrium}

Under rational expectations, the aggregate divorce rate, $d$, implied by the divorce decisions of the agents who expect a remarriage rate $p$ must be consistent with these expectations. Given independence of the shocks, the proportion of divorcees available for remarriage equals the probability that each couple will divorce. Hence, the equilibrium condition is:

$$
p=\phi\left[F\left(\theta^{*}(p)\right)\right]=\phi[F(-y(1-p))]
$$

Because both sides of (8) increase in $p$, there may be multiple equilibria. Multiplicity reflects the self-fulfilling nature of divorce expectations. If many couples are expected to divorce at the end of period 1, the prospects of remarriage are high. Divorce is then less costly, and each particular couple is more likely to split. Conversely, if the divorce rate is expected to be low, then divorce entails a large loss and is less likely to take place, which ex post confirms the initials beliefs. Increasing returns in matching are crucial for this reinforcement mechanism. 


\subsubsection{Welfare}

Having assumed identical individuals, the expected lifetime utility, evaluated at the time of first marriage, is the same for all members of society and given by

$$
\begin{aligned}
W & =2 y+\operatorname{Pr}\{\text { no divorce }\}[2 y+E\{\theta \mid \text { no divorce }\}]+\operatorname{Pr}\{\text { divorce }\}\left[2 y+\theta^{*}((2 .) 9)\right. \\
& =4 y+\int_{\theta^{*}(p)}^{\infty} \theta f(\theta) d \theta+F\left(\theta^{*}(p)\right) \theta^{*}(p) .
\end{aligned}
$$

Differentiating w.r.t. $\theta^{*}(p)$, we get

$$
\frac{\partial W}{\partial \theta^{*}(p)}=F\left(\theta^{*}(p)\right)>0
$$

which is the usual envelope result. An increase in the expected gains from divorce raises welfare in all states in which one would choose to divorce; the additional impact on welfare through the induced change in the divorce decision is negligible, because divorce is chosen optimally. Hence, the marginal divorcee is indifferent between leaving the marriage and staying. We conclude that

Proposition 1. Equilibria with higher divorce-remarriage rates are associated with higher welfare for all participants in the marriage market. 
The intuition is that a higher divorce rate facilitates remarriage and provides both partners with a better option to recover from bad matches. The Pareto ranking of equilibria is a consequence of three basic features of the model: increasing returns in matching, divorce at will and perfect symmetry of all agents which implies that separations are always efficient. If the partners were bound by law not to separate then each person expect to receive a life time utility of $4 y$. The option to divorce raises the expected value of marriage by

$$
\int_{\theta^{*}(p)}^{\infty} \theta f(\theta) d \theta+F\left(\theta^{*}(p)\right) \theta^{*}(p)=\int_{-\infty}^{\theta^{*}(p)} f(\theta)\left(\theta^{*}(p)-\theta\right) d \theta
$$

Thus, marriage is not motivated only by the economic gains from sharing public goods but also by the option to sample from the distribution of non monetary gains and to leave the marriage if a bad draw is revealed. One can therefore apply results from option theory and show that a mean preserving increase in spread raises the equilibrium divorce-remarriage rates and is welfare enhancing. A more favorable meeting function also raises the divorce-remarriage rates and welfare.

The result that a higher divorce rate can be beneficial sounds surprising, given the strong bias in favor of marriage that we embedded in the model, having assumed that all goods in the household are public and can be jointly consumed 
by both partners. But this result holds as long as separations are voluntary and the externalities in the marriage market are positive. One exception arises if partners to marriage have different evaluations of the quality of marriage. In this case, separations may be inefficient, because consumption in the family is public and there is way to transfer utility to the unhappy partner by giving up consumption. In this case, the person with the lower evaluation who initiates the divorce still gains if the aggregate divorce rises but the spouse left behind may lose, especially if the prospects for remarriage are low (see Chiappori and Weiss, 2003). Similar issues arise if men and women have different incomes and expect different gains from divorce.

The main concern with higher divorce rates is associated with the impact on children. The basic problem is that children are not independent agents in the divorce and remarriage decisions and they may be harmed even if the parents fully internalize their welfare in making marital choices. Another issue is that children have specific needs such as mother's time, which raises the issue how to allocate family resources between parents' and children's needs. We now turn to examine these issues in detail. 


\section{Marriage and divorce with children}

The production of children is a major reason for marriage. However, investment in children often creates ex-post differences between otherwise identical men and women. The mother is the one who gives birth and it is generally considered to be more capable of taking care of the children, at least initially. This basic difference may have large economic consequences. If the couple produces children, the mother often reduces her work in the market and, as a consequence, her future earning capacity is reduced. Thus, wage differences between men and women are created endogenously as a consequence of having children. We, therefore, modify the model above, and assume that all men have income, $y$;, all women have income $z$ and $z<y$.

The ex-post asymmetry between parents has strong implications for division of labor within households and, consequently, for the divorce decision, the options for remarriage and the incentive to produce children (see Becker, 1991, Ch. 2). We assume here that fertility is exogenous and all couples choose to have children even in the absence of any transfers. We focus our attention on the agency problems that arise in caring for children and their relation to the aggregate conditions in the marriage market. 


\subsection{Preferences}

A family with children spends its income on two goods; an adult good $a$ and a child good $c$. The adult good $a$ is a public good for all members of the same household and the child good $c$ is private to the children.

The (aggregate) utility of the children is

$$
u_{c}=\alpha a+g(c)
$$

where $\alpha$ is the marginal benefit of children in the adult good, $0 \leq \alpha<1$, and $g(c)$ is increasing and strictly concave.

The utility of a single parent $j$ is

$$
u_{j}=a_{j}+u_{c}
$$

if the parent is single and

$$
u_{j}=a_{j}+u_{c}+\theta_{j}
$$

if the parent is married.

Children are public good for their natural parents even if the children and parents live apart. Adult consumption and match quality are household public 
goods. Any two married individuals who live in the same household share the same value of $a$ and $\theta$. Thus, parents who live together in an intact family have the same value of $a$ and $\theta$. If the parents divorce and live apart in different households, they will have different value of $a$ and $\theta$. In either case, they have the same utility from the child, $u_{c}$.

\subsection{Legal framework}

We assume that the mother is always the custodial parent and discuss two types of payment: a child support payment $s$ that the wife receives if a separation occurs, independently of the subsequent marital status of the parents and an alimony payment $\sigma$ that is paid only if the mother remains single. The child support payment $s$ is determined by law, while the additional payment $\sigma$ is freely contracted upon by the parties; however, it has to be non negative, so that it cannot undo the children support payment mandated by law. We further assume that the payments that the mother receives cannot be earmarked and hence can be freely reallocated in the new household which she forms.

A common legal practice is to set children support at a level that would guarantee a standard of living similar to that obtained under marriage. In the framework presented here, this idea is captured by a mandatory payment $s$ that is 
large enough to potentially restore the same level of child expenditures as under marriage. However, because child support is fungible and child expenditures (especially time spent with children) are not easily verifiable, it remains to determine what will be actually spent on the children (Mnookin and Kornhauser, 1979).

\subsection{The allocation of household resources}

The allocation of household income between the adult and child goods depends on the household structure and the post divorce transfers.

\subsubsection{Intact family}

If the parents remain married, they maximize their common utility give a joint budget constraint. That is,

$$
\max _{a, c}(1+\alpha) a+g(c)+\theta
$$

s.t.

$$
a+c=y+z .
$$

In an interior solution,

$$
g^{\prime}(c)=1+\alpha .
$$


We denote by $c^{*}$ be the unique solution to (17) and assume that

$$
z<c^{*}<y+z,
$$

which means that the income of the mother, $z$, is not sufficient to support the optimal level of child expenditures, while the pooled income of the two parents $y+z$ is large enough to support the children and still leave some income for

adult consumption. We shall assume, however, that the mandated child support payment is set at $s=c^{*}-z$ so that a divorced mother has the required resources to maintain the child consumption at the "accustomed level" during marriage.

\subsubsection{Mother remains single}

In this case, the mother solves

$$
\max _{a, c} a(1+\alpha)+g(c)
$$

s.t.

$$
a+c=z+s+\sigma .
$$

Given the quasi linear structure of preferences, the choice between adult con- 
sumption and child goods follows a very simple rule: The mother spends all her income, $z+s+\sigma$, on the children if her income is lower than the children's "needs", as represented by $c^{*}$. If her total income exceeds $c^{*}$ then the mother will spend $c^{*}$ on children and the rest on herself. Having assumed $s=c^{*}-z$, child expenditures in a single mother household is the same as in intact family, implying that the children's utility is $a \sigma+g\left(c^{*}\right)$ and the mother's utility is $(1+\alpha) \sigma+g\left(c^{*}\right)$.

\subsubsection{Mother remarries}

If the custodial mother remarries, the problem becomes more complicated because of the involvement of a new agent, namely the new husband of the mother. It is possible that the new husband cares about the new child in the same way as the father and, therefore, a remarried couple will behave in the same manner as an intact family, implying the same welfare for the mother and her children. In this case, the father can free ride on the new husband and has no incentive to transfer to his ex-wife. However, by nature, parents care more about their natural children. To simplify, we assume here that the new husband derives no utility at all from the step children, which means that the child good is a private good for the wife in the new household. If $c>c^{*}$, both partners agree that the marginal dollar should be spent on the adult good. If, however, $c<c^{*}$, then an increase in 
the amount spent on the child good raises the utility of the mother, because she values this expenditure more than the forgone adult good, while the benefit for the new husband is nil. In this range, there is a conflict between the mother and her new husband and the level of $c$ must be determined by bargaining.

We apply here the Nash bargaining solution. Since, by assumption, the new husband cares only about the adult good that he receives in the new household and his payments to the ex-wife and thus the utility of his children are independent of his marital status, his gain from remarriage is the additional adult good that he receives upon remarriage

$$
z+s-c
$$

The expected utility gain of the mother from remarriage consists of the additional adult consumption and the change in her utility from child expenditures.

$$
g(c)+(1+a)\left(z+y-(1-p) \sigma^{-}-c\right)-\left[(1+\alpha) \sigma+g\left(c^{*}\right)\right]
$$

where $\sigma^{-}$is the payment that the new husband promised to pay his ex-wife if she remains single. Now suppose that upon meeting and prior to remarriage, the mother and new husband bargain on child expenditures, reaching some binding agreement. Applying Nash's solution, the bargaining outcome is influenced by the 
commitments that the new husband and the father made to their ex-wives. The larger are these commitments, the higher will be the expenditure on the child (see Chiappori and Weiss 2005).

\subsection{Determination of commitments.}

Expecting a remarriage rate, $p$, each father chooses an optimal level of commitment, taking the commitments of others as fixed. Chiappori and Weiss (2005)) show that under plausible conditions (e.g., when $g(c)$ is quadratic) equilibria of the commitment game are attained at the boundaries, where all fathers either do not commit at all or commit to pay an amount

$$
\sigma=\frac{y-s}{2-p} \equiv \sigma(p) .
$$

This level of commitment is the maximal payment which is incentive compatible with remarriage. In fact, each father promises the mother an amount that is sufficiently high to keep her indifferent between remarriage and remaining single, given that other potential mates make the same commitment to their ex-wives. In this manner, each father ensures that the level of child consumption upon remarriage is set at the efficient level $c=c^{*}$ and extracts all rents from the 
prospective mate of the mother upon remarriage. The reason why symmetric equilibria occur at the boundary is that the Nash bargaining outcome is convex in the threat points if $g^{\prime \prime \prime}(c) \geq 0$.

It can be further shown that equilibria with full commitments, $\sigma=\sigma(p)$, arise if the remarriage probability $p$ is sufficiently high, while for sufficiently low values of $p$ no commitments are made and $\sigma=0$. Fathers are more willing to commit on a payment that is conditioned on the event that the mother remains single if the probability of such event is low, because such promises are then carried out less often and are more likely to yield benefits. In this regard, the probability of remarriage serves a coordination device that induces fathers to behave similarly in terms of their commitments.

\subsection{Divorce and remarriage}

Having observed the realized quality of the current match and anticipating the post divorce commitments, each spouse may consider whether or not to continue the marriage. Under divorce at will, the marriage breaks if

$$
u^{*}+\theta<\max \left\{E\left(u_{m}\right), E\left(u_{f}\right)\right\},
$$


where $E\left(u_{m}\right)$ and $E\left(u_{f}\right)$ are the expected utility of the mother and father at divorce and $u^{*}$ is the common utility of the husband and wife if the marriage continues, not incorporating the quality of the match. Note that this divorce rule is different from the more familiar condition

$$
2\left(u^{*}+\theta\right)<E\left(u_{m}\right)+E\left(u_{f}\right)
$$

that would apply if utility is transferable within couples. Our simplifying assumption that all consumption in an intact family is public precludes compensation within couples that would "bribe" the parent with the better outside options to remain in the marriage. With full commitments, however, $E\left(u_{m}\right)=E\left(u_{f}\right)$ and the two conditions coincide.

We denote $\theta_{0}(p)$ and $\theta_{1}(p)$ the critical values of $\theta$ that would trigger divorce without and with commitment, respectively. These two functions generally increase in the expected remarriage rate, although $\theta_{0}(p)$ may decline in $p$ if $\alpha$ is low and the reduction in $c$ upon remarriage is large enough. The main point here is that the mother may remarry even if she expects a reduction in $c$, provided that she is compensated through the increase in her adult consumption, $a$. Thus, the child welfare may decline upon remarriage which can then reduce the welfare of 
the father too. Because of the higher income of the father, $E\left(u_{f}\right)>E\left(u_{m}\right)$ when $\sigma=0$, implying that the father determines the divorce outcome. Hence, if the father loses from a higher remarriage rate, $\theta_{0}(p)$ will decline in $p$. In any case, we have that $\theta_{1}^{\prime}(p)>\theta_{0}^{\prime}(p)$.

\subsection{Equilibrium}

The equilibrium conditions are now

$$
p=m=\phi\left[F\left(\theta_{0}^{*}(p)\right)\right] .
$$

if $p$ is lower than some critical value $p_{0}$ and induces no commitments and

$$
p=m=\phi\left[F\left(\theta_{1}^{*}(p)\right)\right] .
$$

if $p$ is larger than some critical value $p_{1}$ and induces full commitment. Again, the model may have multiple equilibria: a low divorce-remarriage equilibrium without commitments, $\sigma=0$, and a high divorce -remarriage equilibrium, with full commitments, $\sigma=\sigma(p)$. It can be shown that children may in fact be better off in the high divorce-remarriage equilibria because of the stronger incentives for fathers to commit (see Chiappori and Weiss, 2005). 


\section{Conclusion}

Broadly viewed, divorce is a corrective mechanism that enables the replacement of bad matches by better ones. The problem, however, is that private decisions may lead to suboptimal social outcomes because of the various externalities that infest search markets. These externalities exist at the level of a single couple and the market at large. In the models outlined above, those who initiate the divorce fail to internalize the interest of their spouse in continued marriage and the custodial mother that remarries fails to internalize the impact on the father. Moreover, children may suffer even if their welfare is fully internalized, because the child's welfare is only one consideration in the parents' marital choices. At the market level, a person who chooses to divorce fails to take into account the impact on the remarriage prospects of others, and if commitments are made, on the quality of prospective mates. We have shown that the problems at the couple's

level can be resolved by voluntary commitments that entail efficient level of child expenditure and efficient separation. However, such commitments are made only if the expected remarriage rate is sufficiently high. 


\section{References}

[1] Becker, Gary (1991), Treatise on the Family, Harvard University Press.

[2] Chiappori, Pierre-Andre and Yoram Weiss (2003), "Marriage Contracts and Divorce: An Equilibrium Analysis," University of Chicago, unpublished manuscript

[3] Chiappori, Pierre-Andre and Yoram Weiss (2005), "Divorce, Remarriage and Child Support," Tel Aviv University, unpublished manuscript.

[4] Mnookin, Robert and Lewis Kornhauser (1979), "Bargaining in the Shadow of the Law," Yale Law Journal, 88, 950-997.

[5] Mortensen, Dale (1988), "Matching: Finding a Partner for Life or Otherwise," American Journal of Sociology, 94 (supplement), s215-s240. 